of 201 persons were killed, 29 were declared missing, and 83 people were wounded seriously. The number of dead and missing was equal to $4 \%$ of the island's population. An emergency transport system using helicopters was implemented and many victims were transferred to Hokkaido Island.

3. On 12 October 2004, a joint seminar between Indonesia and Japan sponsored by JICA involving the emergency medical teams relative to the emergency medical care that should be provided during a sudden impact disaster was held in Jakarta. Coordination between Indonesia, Malaysia, and the Philippines were discussed with reference to the use of a communication satellite. Two months after this discussion, the Sumatra earthquake occurred. The early medical mission was welcomed in Indonesia and coordinated with Indonesian medical staff.

Conclusion: Japan not only provided JMTDR, but also provided financial aid. An Indian Ocean tsunami-warning network must be established as soon as possible; hopefully it will operate like the Pacific Ocean tsunami-warning networks.

Keywords: Banda Aceh; coordination; earthquake; Indonesia; Japan; Japanese Disaster Relief (JDR); Malaysia; Philippines; tsunam; warning systems

Prehosp Disast Med 2005;20(3):s147-s148

\section{Lesson from Simeulue Island}

S. Otsu; ${ }^{1}$ M. Samion ${ }^{2}$

1. Japanese Red Cross Society Wakayama Medical Center, Japan

2. Palang Meran Sindonesia, Indonesia

Introduction: Simeulue is located in southwest Aceh Province and was the island closest to the epicenter of the 26 December 2004 earthquake. This study seeks to describe how the islanders coped with the tsunami disaster, and suggests an appropriate way of supporting disaster areas. Amazingly, in spite of Simeulue's location, only a few of the island's 79,000 people were killed. This was because residents, remembering tales from their elders about huge waves following large earthquakes, fled from the shores before the tsunami hit. In the early stages after the tsunami, only a few organizations provided relief operations on Simeulue. Palang Meran Indonesia (PMI) started a mobile health clinic on 15 January and was the first and the only organization to conduct curative health activities in the island. On 30 January, the Japanese Red Cross Society (JRCS) joined the PMI's efforts.

Methods: PMI and JRCS operated mobile health clinics. Islanders were interviewed, the general condition of affected villages was examined, and patients' records were abstracted.

Results: When the magnitude 9.0 earthquake struck the island, islanders escaped from the beach as they followed their oral tradition. This reaction resulted in an incredibly small number of victims. While only limited relief items were provided to the island, local residents built temporary shelters using pieces of wood. Chronic diseases were the most common illnesses treated in the mobile health clinics.
Conclusion: External relief operations sometimes underestimate the capacity of local communities to care for themselves. The case of Simeulue Island presents a challenge to international relief operations of tsunami disasters.

Keywords: Aceh Province; capacity; chronic diseases; earthquake; mobile health clinics; relief; Simeulue Island; tsunami Prehosp Disast Med 2005;20(3):1148

\section{Community Health Services Clinic in Bangmuang Evacuation Center in Phang Nga Province in Thailand during the First Month following the Tsunami: A Possible Model of Primary Care in a Rescue Center during a Disaster \\ Y. Bar Dayan;, ${ }^{1}$ D. Shvarts; ${ }^{2}$ A. Goldberg;, ${ }^{2}$ I. Ashkenasi; ${ }^{3}$ G. Nakash; ${ }^{1}$ R. Pelts, ${ }^{1}$ Y. Levi ${ }^{3}$ \\ 1. IDF Home Front Command, Israel \\ 2. Faculty of Health Sciences, Ben Gurion University, Israel \\ 3. IDF Medical Corps, Surgeon General Headquarters, Israel}

Introduction: On 26 December 2004 at 09:00 hours, an earthquake with a magnitude of 9.0 on the Richter scale struck the area off the western coast of northern Sumatra, triggering massive tidal waves (tsunami). The tsunami waves inundated costal areas in countries all around the Indian Ocean rim including Thailand, causing destruction of infrastructure and a huge number of fatalities and injuries. In Thailand, on 25 January 2005, 5,388 fatal cases were confirmed, 3,120 people were reported missing, and 8,457 people were wounded.

Objective: To study the function and patient characteristics of a health clinic erected in an evacuation center following the natural event.

Methods: The IDF home front command medical department sent a research delegation to study the response of the medical system in Thailand to the disaster. The delegation included three physicians and a population behavior sociologist, experienced in hospital preparedness for disaster and emergency medicine. The delegation worked from 29 January-04 February 2005. On 02 February 2005, the delegation met with Thai healthcare officials and visited a community health clinic that was erected in an evacuation center in Bangmuang in the province of Phang Nga. The delegation met and questioned the staff of the health clinic and reviewed patient logs from 05 January-02 February 2005. The methods of research included: (1) open and closed questionnaires; (2) reading debriefing reports; and (3) observation of the infrastructure of the medical facility. Results: The erection of evacuation centers commenced on the day following the tsunami. Such a center was erected in Bangmuang. The center housed 390 families and a total of 1,859 inhabitants. A healthcare clinic was set up in a tent in the center of the camp in order to provide primary health care for the inhabitants. The clinic was staffed by volunteer nurses from Thai hospitals that rotated on a weekly basis. Operating hours were 08:00-20:00 hours, and a visiting physician staffed the clinic from 08:00-14:00 hours. The average patient volume was $80-100$ visits per day: around $5 \%$ of the camp population that visited the clinic every day. Most visits occurred during the physician 